\title{
Novel COVID-19 Outbreak: The Pandemic of the Decade
}

\author{
Tabassum Zafar* \\ Department of Bioscience, Barkatullah University, India
}

*Corresponding author: Tabassum Zafar, Department of Bioscience, Barkatullah University, Bhopal, Madhya Pradesh, 462026, India, Email id: tztabassumzafar@gmail.com

\section{Editorial}

Volume 5 Issue 2

Received Date: March 25, 2020

Published Date: April 02, 2020

DOI: $10.23880 /$ act-16000184

\section{Editorial}

Novel coronavirus-19 (nCoV-19) is a positive-sense single-stranded RNA virus that belongs to the virus family responsible to spread severe acute respiratory syndrome (SARS) [1]. This virus consists of envelope protein (E-protein), nucleocapsid protein (N-protein), spike protein (S-protein), membrane protein (M-protein) and a number of accessory open reading frame proteins (ORF proteins). Angiotensin converting enzyme-2 (ACE2) is the prime endogenous membrane protein that plays an important role in nCoV-19 infection. The virus binds to its host via its trimeric spike glycoprotein structure, which is ten times stronger attachment than SARS [2]. Now, we all are under the threat to face the emerging pandemic of nCoV-19 outbreak, which declared as Public Health Emergency of International Concern by World Health Organization (WHO) [3].

This latest pandemic has been emerged from the Wuhan city of China and currently approximately one hundred and eighty countries are dealing with the complications of outbreak. The common symptoms like throat soreness, runny nose, sneezing, cough, cold, difficulty in breathing, muscle pain, diarrhea accompanied with fever made the pandemic less identifiable in early stages during the initially outbreak [4]. Transmission of nCoV-19 primarily occurred, when respiratory droplets like saliva, coughs and sneeze come in contact with new person within a range of about three feet's. Face oral transmission and direct contact transmission are also some possible ways that found equally responsible for the outbreak.

During the stage I transmission, visitors from Wuhan get transmitted and carries the infection to their native countries. This stage II transmission, which also termed as local transmission these primary carriers and visitors spread the infection around their local proximities while traveling or after reaching to their native places. White stage III transmission, which also considered the community transmission virus infection spread very fast in an indirect and multiplying way. During stage III transmission phase the nCoV-19 spread among those people who neither travelled to infected area nor comes in direct contact with infected patients. These carriers play an important role in stage IV transmission, which is severe and deadly [5]. The last stages are epidemic stage, where the outbreak of nCoV-19 turned uncontrolled and massive. Within no time the virus spread and affects the mass population without any endpoint. If we considered the global scenario all types of transmissions are clearly visible. There are countries who massively destroyed by $n \mathrm{CoV}-19$, while there are also few countries that are trying to cope up with stage I and stage II transmissions [6].

While the world is facing an emergency medically, scientifically, socially and emotionally, we must keep faith that soon some new drugs will be available to treat the disastrous outbreak. We must acknowledge the support of medical practitioners, researchers and essential suppliers for their endless helping hand. It's the right time to adopt the social sanitation habits. Social distancing for a limited period of advised time could be an effective way to break the transmission chain of the virion. Instead of being panic we have to look after many questions that this pandemic has thrown toward the globe. While team of researchers consistently investigating the new domain related to $\mathrm{nCoV}$ 19 pandemic for all the researchers it's the time to think critically and behave scientifically. We must ask ourselves that what social and scientific contribution we can add to relieve this global emergency at our front? For the time being stay safe, stay healthy, and stay positive.

\section{References}

1. Moorthy V, Restrepo AM, Preziosi MP, Swaminathan S (2020) Data sharing for novel coronavirus (COVID-19) Bull World Health Organ 98(3): 150.

2. Wrapp D, Wang N, Corbett KS, Goldsmith JA, Hsieh C, et al. (2020) Cryo-EM structure of the 2019-nCoV spike in 
the prefusion conformation. Science. $367(6483)$ : 1260 1263.

3. Wee SL, McNeil DG, Hernandez JC (2020) W.H.O. Declares Global Emergency as Wuhan Coronavirus Spreads. The New York Times. Archived from the original on 30 January 2020.

4. Chan JF, Yuan S, Kok KH, To KK, Chu H, et al. (2020) A familial cluster of pneumonia associated with the 2019 novel coronavirus indicating person-to-person transmission: a study of a family cluster. The Lancet 395 (10223): 514-523.

5. Wang HJ, Du SH, Yue X, Chen CX (2020) Review and Prospect of Pathological Features of Corona Virus Disease. J Forensic Med 36(1): 16-20.

6. Zou L, Ruan F, Huang M, Liang L, Huang H, et al. (2020) SARS-CoV-2 Viral Load in Upper Respiratory Specimens of Infected Patients. N Engl J Med 382: 1177-1179. 